\title{
Joint Effusion
}

National Cancer Institute

\section{Source}

National Cancer Institute. Joint Effusion. NCI Thesaurus. Code C49052.

Abnormally increased amount of fluid in a joint cavity, usually as a result of joint inflammation. 